\title{
Development of Jaw and Deciduous Teeth in Japanese Children

\author{
-Comparing Size of Crown and Alveolar Area between \\ Today and 40 Years Ago-
}

\author{
Tetsuhide Makiguchi $^{1)}$, Hiroki Imai ${ }^{1)}$, Aiko Arakawa ${ }^{2)}$, Ayako Tashiro ${ }^{1)}$, \\ Takuro Yonezu ${ }^{1)}$ and Seikou Shintani ${ }^{1)}$ \\ ${ }^{1)}$ Department of Pediatric Dentistry, Tokyo Dental College, \\ 2-9-18 Kanda-Misakicho, Chiyoda-ku, Tokyo 101-0061, Japan \\ 2) $3 D$ ! Co., Ltd., \\ 5-21-1-307 Inage Kaigan, Mihama-ku, Chiba 261-0005, Japan
}

Received 26 September, 2017/Accepted for publication 5 December, 2017

\begin{abstract}
The purpose of the present study was to investigate change in the size of the jaw and deciduous teeth in Japanese children over the past 40 years by performing measurements on plaster models of the dental arch obtained from children born between 2007 and 2009 (2000s group) and children born between 1968 and 1974 (70s) group. A total of 61 children were enrolled in the 2000s group, comprising 25 boys (average age, 4 years 5 months) and 36 girls (average age, 4 years 4 months), and 93 children in the 70 s group, comprising 45 boys ( 4 years 6 months) and 48 girls ( 4 years 4 months). The mesiodistal width of the crown, dental arch width, dental arch length, dental arch height, and available arch length in these groups were measured using a 3D measurement system and the sums of the mesiodistal width of the crown and tooth size-arch length discrepancies calculated. The results of the two groups were statistically compared and the following conclusions reached: the size of deciduous teeth has not changed statistically over the last 40 years; the size of the dental arch has decreased in boys $(p<0.01)$, while remaining approximately the same in girls; and the tooth size-arch length discrepancy has decreased, especially in boys $(p<0.01)$. These results indicate that the interdental spaces of the deciduous dentition have decreased, increasing the risk of crowding in Japanese children.
\end{abstract}

Key words: Infants - Deciduous dentition — Deciduous teeth — Development Growth

This paper was a thesis submitted to the Graduate School of Tokyo Dental College by Dr. T. Makiguchi. 


\section{Introduction}

Conservation of the primitive morphology means that little change occurs in the crown of deciduous teeth compared with that in the permanent teeth $^{5,7)}$. Similarly, little change is observed in the morphology of the deciduous dental arch compared with in the permanent dentition, as the former is barely influenced by environmental factors ${ }^{5,10,13)}$. On the other hand, in the case of children, rapid environmental change, such as in diet, impacts both physical and psychological development, including in the oral and dental organs ${ }^{9,14)}$. One earlier study compared plaster models of the deciduous dentition obtained from Caucasians between now and 50 years ago. The results revealed that the mesiodistal width of the crown was either the same or slightly larger, and that the discrepancy in tooth sizearch length decreased in both sexes. They also showed a marked increase in crowding in the mandibular deciduous dentition ${ }^{15}$.

Some studies have reported differences in the dentition between past and present in Japanese populations ${ }^{1-3,8)}$. Few studies have compared differences in the sizes of the deciduous teeth and dental arch between past and present in such a population, however.

The purpose of the present study was to investigate change in the size of the deciduous teeth and dental arch and tooth size-arch length discrepancies in Japanese children over the last 40 years.

\section{Materials and Methods}

\section{Study materials}

1) Group born between 1968 and 1974

A total of 93 dental arch plaster models were obtained from 45 boys and 48 girls who had normal occlusion on impression-taking at the age of 4 years and 6 months (boys), at the age of 4 years and 4 months (girls). All these children were born between 1968 and 1974 (hereafter, 70s group). Sampling was performed with the agreement of the child and guardian. Any damage, caries, or restora- tion that might have skewed the measurements meant exclusion from the study.

2) Group born between 2007 and 2009

A total of 61 dental arch plaster models were obtained from children born between 2007 and 2009 (hereafter, 2000s group), comprising 25 from boys (average age, 4 years 5 months) and 36 from girls (average age, 4 years 4 months) with normal occlusion. Sampling was performed with the agreement of the child and guardian. Any damage, caries, or restoration that might have skewed the measurements meant exclusion from the study.

The present study was approved by the Ethics Review Board of Tokyo Dental College (Approval number: 295).

\section{Methods}

1) Measurement methods

All the dental arch models were measured using a 3D measurement system $\left(\right.$ DORA $^{\circledR}$ by 3D! Co., Ltd., Tokyo, Japan). All the models were imported to a computer by a trained engineer and measurement performed using this system which allows measurement to an accuracy of within 10 to $30 \mu \mathrm{m}$. Undercut and areas difficult to measure were enlarged or sectioned using CAD to ensure accuracy.

\section{2) Measurement sites}

The mesiodistal width of all the deciduous teeth crowns was measured and the sums were calculated. The average value for each tooth type in each model was calculated to determine mesiodistal crown width. To determine dental arch size, measurement was performed based on the standards recommended by the Japanese Society of Pediatric Dentistry in 1993 (Fig. 1) ${ }^{10)}$. Dental arch width (6 measurement points in each jaw), dental arch length (3 measurement points in each jaw), and dental arch height (2 measurement points) were determined. The measurement sites and reference points were as follows:

(1) Dental arch width

a: the distance between the maxillary and mandibular bilateral canine cusps $\left(\mathrm{C}_{\mathrm{C}}-\mathrm{C}_{\mathrm{C}}\right)$;

$\mathrm{b}$ : the distance between the lowest points in the cervical area of the palatal (lingual) side 
of the maxillary and mandibular deciduous canines $\left(\mathrm{C}_{\mathrm{L}}-\mathrm{C}_{\mathrm{L}}\right)$;

c: the distance between the buccal cusps of the maxillary bilateral first deciduous molars (D-D), and that between the buccal terminal sulci of the mandibular bilateral first deciduous molars (D-D);

$\mathrm{d}$ : the distance between the lowest points in the cervical area of the palatal side of the maxillary bilateral first deciduous molars $\left(\mathrm{D}_{\mathrm{L}}-\mathrm{D}_{\mathrm{L}}\right)$, and that between the sub-lingual sulci of the lingual mesiodistal cusps of the mandibular bilateral first deciduous molars $\left(\mathrm{D}_{\mathrm{L}}-\mathrm{D}_{\mathrm{L}}\right)$;

e: the distance between the buccal terminal sulci of the maxillary bilateral second deciduous molars (E-E), and that between the mesial buccal terminal sulci of the mandibular bilateral second deciduous molars (E-E); and

$\mathrm{f}$ : the distance between the lowest points in the cervical area of the palatal (lingual) side of the maxillary and mandibular bilateral second deciduous molars $\left(\mathrm{E}_{\mathrm{L}}-\mathrm{E}_{\mathrm{L}}\right)$.

(2) Dental arch length

g: the length of the perpendicular line from the center of the line connecting the labial surface of the bilateral deciduous central incisors to the bilateral deciduous canine cusps $\left(\mathrm{A}-\mathrm{C}_{\mathrm{C}}\right)$;

$h$ : the length of the perpendicular line from the center of the line connecting the labial surface of the bilateral deciduous central incisors to the mesial buccal terminal sulci of the bilateral second deciduous molars (A-E); and

i: the length of the perpendicular line from the center of the line connecting the labial surface of the bilateral deciduous central incisors to the most distal edges of the bilateral second deciduous molars $\left(\mathrm{A}-\mathrm{E}_{\mathrm{D}}\right)$.

(3) Dental arch height

$\mathrm{j}$ : the distance between the interdental papillae of the maxillary and mandibular bilateral deciduous central incisors (dental height); and

$\mathrm{k}$ : the distance between the center of the cervical area of the labial surface of the maxillary and mandibular left deciduous central incisors (ULA-LLA).

Available arch length was calculated by add-

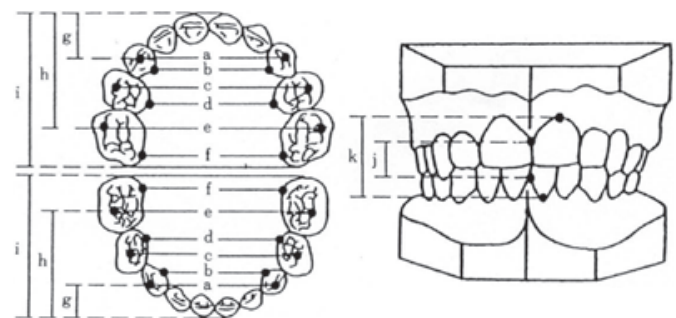

Fig. 1 Measurement sites and reference points for dental arch width, length, and height

Dental arch width

a: the distance between the maxillary and mandibular bilateral canine cusps (Cc-Cc);

$\mathrm{b}$ : the distance between the lowest points in the cervical area of the palatal (lingual) side of the maxillary and mandibular deciduous canines $\left(\mathrm{CL}_{\mathrm{L}}-\mathrm{CL}_{\mathrm{L}}\right)$;

c: the distance between the buccal cusps of the maxillary bilateral deciduous molars (D-D), and that between the buccal terminal sulci of the mandibular bilateral first deciduous molars (D-D);

$\mathrm{d}$ : the distance between the lowest points in the cervical area of the palatal side of the maxillary bilateral deciduous molars $\left(\mathrm{D}_{\mathrm{L}}-\mathrm{D}_{\mathrm{L}}\right)$, and that between the sub-lingual sulci of the lingual mesiodistal cusps of the mandibular bilateral first deciduous molars $\left(\mathrm{D}_{\mathrm{L}}-\mathrm{D}_{\mathrm{L}}\right)$;

e: the distance between the buccal terminal sulci of the maxillary bilateral second deciduous molars (E-E), and that between the mesial buccal terminal sulci of the mandibular bilateral second deciduous molars (E-E);

$\mathrm{f}$ : the distance between the lowest points in the cervical area of the palatal (lingual) side of the maxillary and mandibular bilateral second deciduous molars ( $\left.\mathrm{E}_{\mathrm{L}}-\mathrm{E}_{\mathrm{L}}\right)$.

Dental arch length

$\mathrm{g}$ : the length of the perpendicular line from the center of the line connecting the labial surface of the bilateral deciduous central incisors to the bilateral deciduous canine cusps (A-Cc);

$\mathrm{h}$ : the length of the perpendicular line from the center of the line connecting the labial surface of the bilateral deciduous central incisors to the mesial buccal terminal sulci of the bilateral second deciduous molars (A-E);

i: the length of the perpendicular line from the center of the line connecting the labial surface of the bilateral deciduous central incisors to the most distal edges of the bilateral second deciduous molars (A-ED).

Dental arch height

$\mathrm{j}$ : the distance between the interdental papillae of the maxillary and mandibular bilateral deciduous central incisors (dental height); and

$\mathrm{k}$ : the distance between the center of the cervical area of the labial surface of the maxillary and mandibular left deciduous central incisors (ULA-LLA).

ing A, B, C, and D (Fig. 2). Measurements in both the maxilla and mandible were made in accordance with the criteria below, which were reported in an earlier study ${ }^{15}$ :

$\mathrm{A}$ and $\mathrm{C}$ : the distance between the most 
mesial point of the deciduous central incisor and the most distal point of the deciduous canine.

$\mathrm{B}$ and D: the distance between the most distal point of the deciduous canine and the most distal point of the deciduous second molar.

When there is a space between the central incisors, the most mesial point of the left deciduous central incisor is used as the reference.

Tooth size-arch length discrepancy (TSALD) is calculated by subtracting the sums of the mesiodistal width of the crown from the available arch length.

3) Statistical processing

An unpaired $t$-test was used to establish differences in the mean values between the two groups. Statistical analysis was performed using SPSS version 11.0 software (IBM, Tokyo, Japan). This was done for the mesiodistal width of the crown; the sums of the mesiodistal width of the crown; dental arch width; dental arch length; dental arch height; available arch length; and TSALD. A p value of $<0.01$ or $<0.05$ was considered to indicate significance.

An age difference has been reported in available arch length ${ }^{15}$. The number of cases required was determined by a two-sided test on 5 preliminary cases at a significance level of 0.05 and $80 \%$ power. The difference in the average value for the maxillary deciduous dental arch in boys between the two groups was $2.1 \mathrm{~mm}$, with an estimated standard deviation of 1.9. Therefore, the number of cases required was estimated to be more than 13 . Similarly, the difference in the average value for the mandibular deciduous dental arch between the two groups was estimated to be $2.1 \mathrm{~mm}$, with an estimated standard deviation of 1.9. Therefore the number of cases required was estimated as more than 13 . The difference in the average value for the maxillary deciduous dental arch in girls between the two groups was $1.6 \mathrm{~mm}$, with an estimated standard deviation of 2.1. Therefore, the number of cases required was estimated to be more than 27. The difference in the average

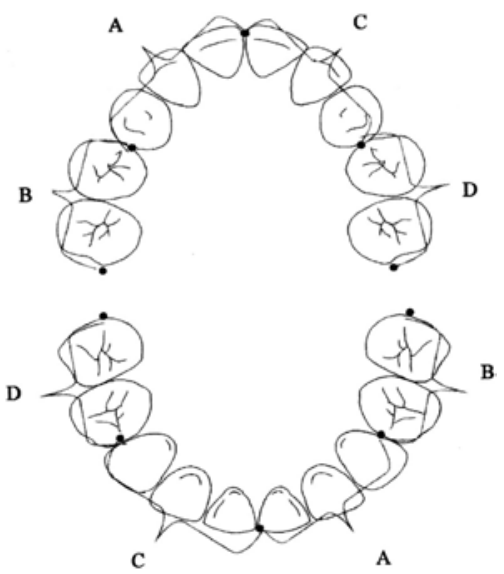

Fig. 2 Measurement points for available arch length A and C: the distance between the most mesial point of the deciduous central incisor and the most distal point of the deciduous canine.

$\mathrm{B}$ and D: the distance between the most distal point of the deciduous canine and the most distal point of the deciduous second molar.

When there is a space between the central incisors, the most mesial point of the left deciduous central incisor is used as the reference.

value for the mandibular deciduous dental arch in girls between the two groups was estimated to be $2.4 \mathrm{~mm}$, with an estimated standard deviation of 3.2. Therefore, the number of cases necessary was estimated to be more than 28.

\section{Results}

\section{Mesiodistal width of deciduous crown}

1) Difference in each tooth type between groups (Table 1)

For boys, the mesiodistal crown width of the maxillary deciduous central incisor $(p<0.01)$, mandibular deciduous central incisor $(\mathrm{p}<0.05)$, and mandibular deciduous lateral incisor $(\mathrm{p}<0.01)$ was significantly larger in the 2000s group. Conversely, the mesiodistal crown width of the maxillary deciduous second molar $(p<0.01)$ was significantly larger in the 70s group. No significant difference was observed in the other tooth types.

For girls, the mesiodistal crown width of the 
Table 1 Mesiodistal width of deciduous tooth crown

\begin{tabular}{|c|c|c|c|c|c|}
\hline \multirow{2}{*}{ Sex } & \multirow{2}{*}{ Jaw } & \multirow{2}{*}{ Tooth } & \multirow{2}{*}{$\begin{array}{c}70 \text { s group } \\
\begin{array}{c}\text { Mean } \pm \mathrm{SD} \\
(\mathrm{mm})\end{array}\end{array}$} & \multirow{2}{*}{$\begin{array}{c}2000 \text { s group } \\
\begin{array}{c}\text { Mean } \pm \mathrm{SD} \\
(\mathrm{mm})\end{array}\end{array}$} & \multirow{2}{*}{$\begin{array}{c}\text { Age } \\
\text { difference }\end{array}$} \\
\hline & & & & & \\
\hline \multirow[t]{10}{*}{ Boys } & Maxilla & A: Deciduous central incisor & $6.58 \pm 0.38$ & $6.75 \pm 0.30$ & $* *$ \\
\hline & & B: Deciduous lateral incisor & $5.51 \pm 0.39$ & $5.50 \pm 0.30$ & \\
\hline & & C: Deciduous canine & $6.63 \pm 0.41$ & $6.76 \pm 0.40$ & \\
\hline & & D: Deciduous first molar & $7.42 \pm 0.49$ & $7.50 \pm 0.43$ & \\
\hline & & E: Deciduous second molar & $9.55 \pm 0.65$ & $9.24 \pm 0.55$ & $* *$ \\
\hline & Mandible & A: Deciduous central incisor & $4.17 \pm 0.36$ & $4.28 \pm 0.22$ & $*$ \\
\hline & & B: Deciduous lateral incisor & $4.68 \pm 0.38$ & $4.85 \pm 0.26$ & $* *$ \\
\hline & & C: Deciduous canine & $5.83 \pm 0.30$ & $5.83 \pm 0.27$ & \\
\hline & & D: Deciduous first molar & $8.41 \pm 0.52$ & $8.34 \pm 0.34$ & \\
\hline & & E: Deciduous second molar & $10.33 \pm 0.50$ & $10.26 \pm 0.46$ & \\
\hline \multirow[t]{10}{*}{ Girls } & Maxilla & A: Deciduous central incisor & $6.53 \pm 0.34$ & $6.60 \pm 0.35$ & \\
\hline & & B: Deciduous lateral incisor & $5.37 \pm 0.30$ & $5.36 \pm 0.36$ & \\
\hline & & C: Deciduous canine & $6.51 \pm 0.35$ & $6.67 \pm 0.27$ & $* *$ \\
\hline & & D: Deciduous first molar & $7.18 \pm 0.38$ & $7.29 \pm 0.35$ & \\
\hline & & E: Deciduous second molar & $9.44 \pm 0.48$ & $9.10 \pm 0.45$ & $* *$ \\
\hline & Mandible & A: Deciduous central incisor & $4.10 \pm 0.30$ & $4.18 \pm 0.41$ & \\
\hline & & B: Deciduous lateral incisor & $4.68 \pm 0.30$ & $4.75 \pm 0.35$ & \\
\hline & & C: Deciduous canine & $5.83 \pm 0.26$ & $5.85 \pm 0.28$ & \\
\hline & & D: Deciduous first molar & $8.17 \pm 0.42$ & $8.16 \pm 0.41$ & \\
\hline & & E: Deciduous second molar & $10.12 \pm 0.39$ & $10.14 \pm 0.53$ & \\
\hline
\end{tabular}

SD: Standard deviation. **p $<0.01 \quad * \mathrm{p}<0.05$

Table 2 Age difference in sums of deciduous crown mesiodistal width

\begin{tabular}{|c|c|c|c|c|}
\hline \multirow{2}{*}{ Sex } & \multirow[b]{2}{*}{ Jaw } & 70 s group & 2000 s group & \multirow{2}{*}{$\begin{array}{c}\text { Age } \\
\text { difference }\end{array}$} \\
\hline & & $\begin{array}{l}\text { Mean } \pm \text { SD } \\
\quad(\mathrm{mm})\end{array}$ & $\begin{array}{l}\text { Mean } \pm \text { SD } \\
(\mathrm{mm})\end{array}$ & \\
\hline \multirow[t]{2}{*}{ Boys } & Maxilla & $71.4 \pm 3.7$ & $71.5 \pm 3.2$ & \\
\hline & Mandible & $66.8 \pm 3.3$ & $67.1 \pm 2.1$ & \\
\hline \multirow[t]{2}{*}{ Girls } & Maxilla & $70.1 \pm 2.5$ & $70.1 \pm 2.6$ & \\
\hline & Mandible & $65.8 \pm 2.5$ & $66.1 \pm 2.4$ & \\
\hline
\end{tabular}

SD: Standard deviation. 
Table 3 Size of dental arch

\begin{tabular}{|c|c|c|c|c|c|c|}
\hline \multirow[b]{2}{*}{ Sex } & \multirow{2}{*}{\multicolumn{3}{|c|}{ measurement point }} & \multirow{2}{*}{$\begin{array}{c}\text { 70s group } \\
\begin{array}{c}\text { Mean } \pm \mathrm{SD} \\
(\mathrm{mm})\end{array}\end{array}$} & \multirow{2}{*}{$\begin{array}{c}\text { 2000s group } \\
\begin{array}{c}\text { Mean } \pm \mathrm{SD} \\
(\mathrm{mm})\end{array}\end{array}$} & \multirow{2}{*}{$\begin{array}{c}\text { Age } \\
\text { difference }\end{array}$} \\
\hline & & & & & & \\
\hline \multirow[t]{20}{*}{ Boys } & Dental arch width & Maxilla & Cc-Cc & $30.93 \pm 1.54$ & $30.13 \pm 2.33$ & \\
\hline & & & $\mathrm{CL}_{\mathrm{L}}-\mathrm{CL}_{\mathrm{L}}$ & $25.49 \pm 1.39$ & $24.80 \pm 1.78$ & \\
\hline & & & D-D & $39.71 \pm 2.02$ & $39.53 \pm 1.92$ & \\
\hline & & & $\mathrm{D}_{\mathrm{L}-\mathrm{D}} \mathrm{D}_{\mathrm{L}}$ & $28.18 \pm 1.35$ & $27.54 \pm 1.49$ & \\
\hline & & & E-E & $47.26 \pm 1.85$ & $46.47 \pm 2.32$ & \\
\hline & & & $\mathrm{EL}_{\mathrm{L}}-\mathrm{EL}_{\mathrm{L}}$ & $30.59 \pm 1.40$ & $30.03 \pm 1.64$ & \\
\hline & & Mandible & $\mathrm{Cc}-\mathrm{Cc}$ & $23.61 \pm 1.66$ & $23.09 \pm 2.04$ & \\
\hline & & & $\mathrm{CL}_{\mathrm{L}}-\mathrm{CL}_{\mathrm{L}}$ & $19.57 \pm 1.30$ & $19.49 \pm 1.59$ & \\
\hline & & & D-D & $31.10 \pm 1.72$ & $33.77 \pm 1.84$ & $* *$ \\
\hline & & & $\mathrm{D}_{\mathrm{L}}-\mathrm{D}_{\mathrm{L}}$ & $25.14 \pm 1.30$ & $24.63 \pm 1.43$ & \\
\hline & & & E-E & $40.05 \pm 1.78$ & $39.54 \pm 2.52$ & \\
\hline & & & $\mathrm{E}_{\mathrm{L}}-\mathrm{E}_{\mathrm{L}}$ & $29.28 \pm 1.25$ & $28.82 \pm 1.46$ & \\
\hline & Dental arch length & Maxilla & A-Cc & $7.98 \pm 0.84$ & $8.55 \pm 1.08$ & $*$ \\
\hline & & & A-E & $23.33 \pm 1.42$ & $22.75 \pm 1.34$ & \\
\hline & & & $\mathrm{A}-\mathrm{E}_{\mathrm{D}}$ & $29.11 \pm 1.48$ & $28.36 \pm 1.24$ & $*$ \\
\hline & & Mandible & A-Cc & $5.46 \pm 0.68$ & $5.45 \pm 0.95$ & \\
\hline & & & A-E & $20.04 \pm 1.23$ & $20.34 \pm 3.71$ & \\
\hline & & & $\mathrm{A}-\mathrm{E}_{\mathrm{D}}$ & $26.57 \pm 1.43$ & $26.04 \pm 0.96$ & \\
\hline & Dental arch height & & Dental height & $3.16 \pm 1.43$ & $4.26 \pm 1.08$ & $* *$ \\
\hline & & & ULA-LLA & $7.61 \pm 1.64$ & $8.49 \pm 1.12$ & $* *$ \\
\hline \multirow[t]{20}{*}{ Girls } & Dental arch width & Maxilla & $\mathrm{Cc}-\mathrm{Cc}$ & $29.63 \pm 1.72$ & $30.13 \pm 1.36$ & \\
\hline & & & $\mathrm{C}_{\mathrm{L}}-\mathrm{C}_{\mathrm{L}}$ & $24.23 \pm 1.64$ & $24.20 \pm 1.23$ & \\
\hline & & & D-D & $38.07 \pm 1.85$ & $38.64 \pm 1.62$ & \\
\hline & & & $\mathrm{D}_{\mathrm{L}}-\mathrm{D}_{\mathrm{L}}$ & $26.73 \pm 1.72$ & $26.95 \pm 1.38$ & \\
\hline & & & E-E & $45.19 \pm 1.76$ & $45.59 \pm 1.53$ & \\
\hline & & & $\mathrm{E}_{\mathrm{L}-\mathrm{E}_{\mathrm{L}}}$ & $28.99 \pm 1.72$ & $29.17 \pm 1.25$ & \\
\hline & & Mandible & Cc-Cc & $22.68 \pm 1.56$ & $22.43 \pm 1.52$ & \\
\hline & & & $\mathrm{CL}_{\mathrm{L}}-\mathrm{C}_{\mathrm{L}}$ & $18.77 \pm 1.26$ & $18.55 \pm 0.99$ & \\
\hline & & & D-D & $30.20 \pm 1.92$ & $32.85 \pm 1.33$ & $* *$ \\
\hline & & & $\mathrm{D}_{\mathrm{L}}-\mathrm{D}_{\mathrm{L}}$ & $24.31 \pm 1.58$ & $23.74 \pm 1.24$ & \\
\hline & & & E-E & $38.62 \pm 1.72$ & $38.20 \pm 1.37$ & \\
\hline & & & $\mathrm{E}_{\mathrm{L}}-\mathrm{E}_{\mathrm{L}}$ & $28.39 \pm 1.49$ & $27.76 \pm 1.38$ & $*$ \\
\hline & Dental arch length & Maxilla & A-Cc & $8.11 \pm 0.74$ & $8.42 \pm 1.14$ & \\
\hline & & & A-E & $22.95 \pm 1.30$ & $22.52 \pm 1.31$ & \\
\hline & & & $\mathrm{A}-\mathrm{E}_{\mathrm{D}}$ & $28.80 \pm 1.25$ & $28.32 \pm 1.43$ & \\
\hline & & Mandible & A-Cc & $5.68 \pm 0.55$ & $5.68 \pm 0.71$ & \\
\hline & & & A-E & $19.96 \pm 0.99$ & $19.73 \pm 1.10$ & \\
\hline & & & $\mathrm{A}-\mathrm{E}_{\mathrm{D}}$ & $26.10 \pm 1.12$ & $25.89 \pm 1.31$ & \\
\hline & Dental arch height & & Dental height & $3.28 \pm 1.48$ & $3.69 \pm 1.35$ & \\
\hline & & & ULA-LLA & $7.60 \pm 1.55$ & $7.95 \pm 1.33$ & \\
\hline
\end{tabular}

SD: Standard deviation. **p $<0.01 \quad * \mathrm{p}<0.05$ 


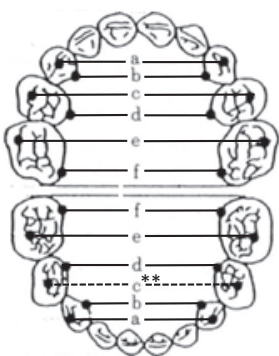

Boys

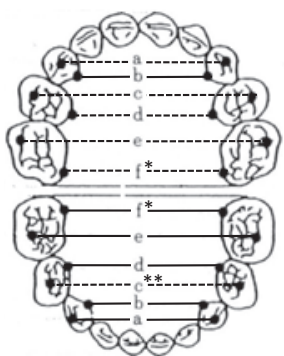

Girls
Fig. 3 Dental arch width (age difference)

Solid line indicates that value of measurement site was greater in 70 s group than in 2000s group; dotted line indicates opposite result.

$* * \mathrm{p}<0.01 * \mathrm{p}<0.05$

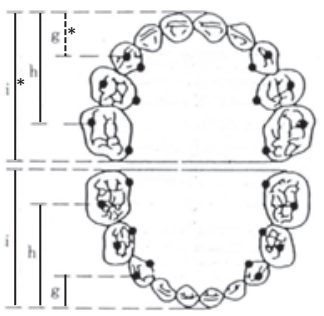

Boys

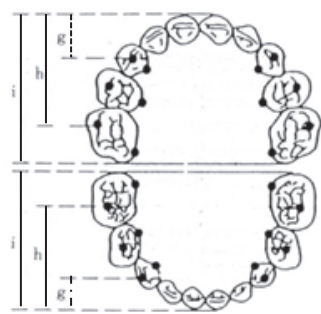

Girls
Fig. 4 Dental arch length (age difference)

Solid line indicates that value of measurement site was greater in 70 s group than in 2000s group; dotted line indicates opposite result. Dashed dotted line denotes similar values between groups. $* \mathrm{p}<0.05$

maxillary deciduous canine $(\mathrm{p}<0.01)$ was significantly larger in the 2000s group, and that of the maxillary deciduous second molar $(\mathrm{p}<0.01)$ was significantly larger in the $70 \mathrm{~s}$ group. No significant difference was observed in the other tooth types.

2) Differences in sums between groups (Table 2)

No significant difference was observed in the sums of the mesiodistal crown width in either sex or jaw between the 70s and 2000s groups.
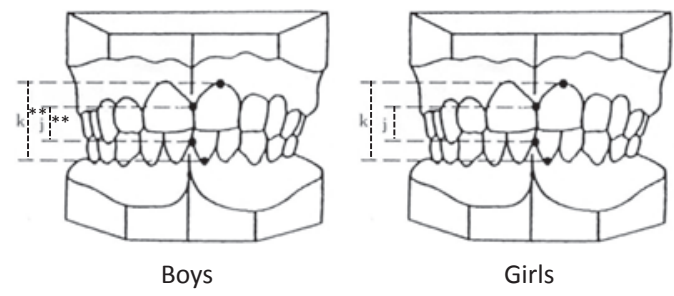

Fig. 5 Dental arch height (age difference)

Dotted line indicates that value of measurement site was greater in 2000 s group than in 70 s group. $* * \mathrm{p}<0.01$

\section{Dental arch size}

1) Differences in dental arch width, length, and height between groups (Table 3)

(1) Dental arch width

As regards dental arch width in boys, the mandibular D-D was significantly greater in the 2000s group $(\mathrm{p}<0.01)$, whereas the other measurements were slightly larger in the $70 \mathrm{~s}$ group or approximately the same. As regards dental arch width in girls, no significant difference was observed in the maxilla, but it was either slightly larger or approximately the same in the 2000s group (Fig. 3). The mandibular D-D was significantly greater in the 2000s group $(p<0.01)$, whereas $\mathrm{E}_{\mathrm{L}}-\mathrm{E}_{\mathrm{L}}$ was significantly greater in the 70s group $(\mathrm{p}<0.05)$. Other measurements were slightly larger in the 70 s group or approximately the same (Fig. 3).

(2) Dental arch length

As regards dental arch length in boys, the maxillary $A-\mathrm{C}_{\mathrm{C}}$ was significantly greater in the 2000 s group $(\mathrm{p}<0.05)$, whereas the maxillary $A-E_{D}$ was significantly greater in the 70 s group $(p<0.05)$. No significant difference was observed in the other dental arch length measurements. No significant difference was observed in dental arch length measurements in girls between the 70 s and 2000s groups (Fig. 4).

(3) Dental arch height

As regards dental arch height in boys, both measurements were significantly larger in the 2000 s group $(p<0.01)$. Although no significant difference was observed in girls, both measurements were slightly larger in the 
Table 4 Age difference in deciduous available dental arch length

\begin{tabular}{|c|c|c|c|c|}
\hline \multirow{2}{*}{ Sex } & \multirow{2}{*}{ Jaw } & 70s group & 2000 s group & \multirow{2}{*}{$\begin{array}{c}\text { Age } \\
\text { difference }\end{array}$} \\
\hline & & $\begin{array}{c}\text { Mean } \pm \text { SD } \\
(\mathrm{mm})\end{array}$ & $\begin{array}{l}\text { Mean } \pm \text { SD } \\
\quad(\mathrm{mm})\end{array}$ & \\
\hline \multirow[t]{2}{*}{ Boys } & Maxilla & $74.1 \pm 3.1$ & $71.9 \pm 2.1$ & $* *$ \\
\hline & Mandible & $68.6 \pm 2.9$ & $66.7 \pm 1.5$ & $* *$ \\
\hline \multirow[t]{2}{*}{ Girls } & Maxilla & $72.0 \pm 2.7$ & $71.2 \pm 2.6$ & \\
\hline & Mandible & $66.7 \pm 2.5$ & $66.1 \pm 2.6$ & \\
\hline
\end{tabular}

SD: Standard deviation. $* * \mathrm{p}<0.01$

Table 5 Age difference in tooth size-arch length discrepancy

\begin{tabular}{|c|c|c|c|c|}
\hline \multirow{2}{*}{ Sex } & \multirow{2}{*}{ Jaw } & 70s group & 2000s group & \multirow{2}{*}{$\begin{array}{c}\text { Age } \\
\text { difference }\end{array}$} \\
\hline & & $\begin{array}{c}\text { Mean } \pm \text { SD } \\
(\mathrm{mm})\end{array}$ & $\begin{array}{c}\text { Mean } \pm \text { SD } \\
(\mathrm{mm})\end{array}$ & \\
\hline \multirow[t]{2}{*}{ Boys } & Maxilla & $2.8 \pm 2.7$ & $0.5 \pm 2.8$ & $* *$ \\
\hline & Mandible & $1.8 \pm 2.6$ & $-0.4 \pm 2.2$ & $* *$ \\
\hline \multirow[t]{2}{*}{ Girls } & Maxilla & $2.0 \pm 2.5$ & $1.1 \pm 2.7$ & \\
\hline & Mandible & $0.9 \pm 2.4$ & $-0.0 \pm 1.8$ & \\
\hline
\end{tabular}

SD: Standard deviation. $* * \mathrm{p}<0.01$

2000s group (Fig. 5).

2) Differences in available arch length between groups (Table 4)

The available arch length in boys was significantly greater in the 70 s group for both the maxilla and mandible $(\mathrm{p}<0.01)$. No significant difference was observed in girls between the 70 s and 2000s groups.

\section{Differences in tooth size-arch length discrepancy between groups}

As can be seen in Table 5, TSALD in boys was significantly greater in the 70s group for both the maxilla and mandible $(\mathrm{p}<0.01)$. No significant difference was observed in TSALD in girls between the 70s and 2000s groups.

\section{Discussion}

\section{Measurement method}

The 3D measurement system used in the present study allows readings to be made with an accuracy of within 10 to $30 \mu \mathrm{m}$. Undercut and areas difficult to measure were enlarged or sectioned using CAD to ensure accuracy. We believe that this system offered sufficient accuracy of measurement for the present purposes based on earlier studies, including one that measured dental plaster models to evaluate its accuracy and found it to be as good as that obtainable with a caliper ${ }^{4,11)}$.

\section{Mesiodistal width of deciduous crown}

1) Differences by tooth type between groups

As regards differences in mesiodistal width of the deciduous crown in boys, only the maxillary second molar was significantly greater in the 70 s group, while the maxillary and man- 
dibular deciduous central incisors and mandibular deciduous lateral incisor were significantly wider in the 2000s group. No major difference was observed overall. In a study carried out in 2002 comparing mesiodistal width of the deciduous crown with that in a population 20 years earlier, little difference was observed in boys ${ }^{6)}$. In the present study, however, 3 incisors were significantly larger and the maxillary second molar significantly smaller in the 2000s group. This suggests that the deciduous frontal teeth have become slightly larger and deciduous molars slightly smaller over the past 40 years.

In one earlier study, the sums of the mesiodistal widths of the mandibular deciduous crowns showed a significant increase in girls ${ }^{15)}$. In another study, the maxillary deciduous central incisors and mandibular deciduous lateral incisors and canines showed a significant increase in the mesiodistal width of the deciduous crown over the past 20 years in girls. All the other tooth types also showed an increase in mesiodistal width of the deciduous crown over the past 20 years, although the difference was not significant ${ }^{6)}$. The results of the present study showed a significant increase in the maxillary deciduous canine and significant decrease in the maxillary deciduous second molar in girls. Although not as marked as in boys, the deciduous frontal teeth in girls showed a slight increase in size, whereas the deciduous molars showed a slight decrease or remained approximately the same. Taken together, this suggests that differences in the mesiodistal width of the deciduous crown were smaller in girls than in boys.

The maxillary deciduous second molars were smaller in the 2000s group than in the 70 s group in both sexes. This suggests that the mesiodistal width of the deciduous maxillary second molars in Japanese children has decreased. This further suggests a relative decrease in the maxillary leeway space. We believe that these changes in the mesiodistal width of the deciduous crown have affected the deciduous dental arch and occlusion in Japanese children.

2) Difference in sums between groups
No significant difference was observed in the sums of the mesiodistal width of the maxillary and mandibular deciduous crowns in either sex between the 70s and 2000s groups. This finding agrees with that of an earlier study comparing the sums of the mesiodistal width of 50 years ago using deciduous dental arch plaster models obtained from Caucasians. They found that the sums of the mesiodistal width of the mandibular deciduous crowns showed a significant increase in girls, but no other significant difference. They reported that the mesiodistal width of the deciduous crown had shown a slight increase or remained approximately the same over the past 50 years ${ }^{15}$. Similarly, in the present study, the sums of the mesiodistal width of the deciduous crown showed little change over the past 40 years in a Japanese population. Considering the previously-described size comparison by tooth type, this suggests that little change has occurred in the sums of the mesiodistal width of the Japanese deciduous crown over the past 40 years.

\section{Dental arch size}

1) Difference in dental arch width between groups

A comparison of deciduous dental arch width between the 70 s and 2000s groups revealed a significant increase in the mandibular D-D only in the 2000s group in boys, whereas all the other measurements were greater in the 70s group, although the difference was not significant. This suggests that the deciduous dental arch width has become slightly smaller or remained approximately the same over the past 40 years.

The results in girls showed a different trend between the maxilla and mandible. While there was little change in maxillary $\mathrm{C}_{\mathrm{L}}-\mathrm{C}_{\mathrm{L}}$, all the other measurements were greater in the 2000s group, although the difference was not significant. In the mandible, however, D-D was significantly greater in the 2000s group, while all the other measurements were greater in the $70 \mathrm{~s}$ group, including $\mathrm{E}_{\mathrm{L}}-\mathrm{E}_{\mathrm{L}}$, which showed a significant difference.

In the maxilla, deciduous dental arch width 
in girls has shown a slight increase or remained approximately the same over the past 40 years, while in the mandible in boys it has shown a slight decrease or remained approximately the same. One earlier study also reported that crowding during the deciduous dentition period showed an increase ${ }^{15)}$. In the present study, although $\mathrm{C}_{\mathrm{L}}-\mathrm{C}_{\mathrm{L}}$ and $\mathrm{C}_{\mathrm{C}}-\mathrm{C}_{\mathrm{C}}$ remained approximately the same in the 2000 s group compared with in the 70 s group in both sexes, the mesiodistal width of the deciduous frontal teeth, including the canines, showed a tendency to be significantly larger in the 2000s group. We believe that this may cause crowding.

2) Difference in dental arch length between groups

A comparison of deciduous dental arch length between the 70s and 2000s groups revealed an increase in 2 (one of them showed a significant difference) of the 6 measurement points in the 2000s group in boys, and an increase in the other 4 measurement points (one of them showed a significant difference) in the 70 s group. This suggests that deciduous dental arch length has become slightly smaller or remained approximately the same in boys over the past 40 years. Although there was no significant difference, 5 of the 6 measurement points showed an increase in the 70 s group in girls. This suggests that the deciduous dental arch length has become slightly smaller or remained approximately the same in girls.

3) Difference in dental arch height between groups

A comparison of deciduous dental arch height between the 70s and 2000s groups revealed significantly larger values in boys in the 2000s groups. This suggests that dental arch length has increased over the past 40 years. We believe that dental attrition may have affected this result due to changes in the soft diet over the past 40 years.

4) Difference in available arch length between groups

Available arch length showed a significant decrease in both the maxilla and mandible in the 2000s group in boys while remaining approximately the same in girls. Considering the previously-described results for dental arch width and length, this suggests that the size of the deciduous dental arch has decreased in boys over the past 40 years. The available arch length was significantly larger in boys $(p<0.01)$ in both the maxilla and mandible in the 70s group, but there was no significant difference in the 2000s group. This suggests that the deciduous dental arch has become significantly smaller in boys while remaining approximately the same in girls over the past 40 years in this Japanese population, leading to a decrease in the difference between sexes.

\section{Difference in tooth size-arch length discrepancy between groups}

The TSALD was significantly greater in both the maxilla and mandible in the $70 \mathrm{~s}$ group in boys and greater in the 70s group in girls. These results were similar to those of an earlier study ${ }^{15}$. This suggests that the interdental space in Japanese deciduous dentition has decreased over the past 40 years, especially in boys. We believe that these results are related to the decrease in deciduous dental arch size. A closed dental arch with little interdental space during the deciduous dentition period results in a higher rate of crowding in the permanent dentition ${ }^{12)}$. The results of the present study suggest that the risk of crowding has increased in the mandible in Japanese children, especially in boys.

\section{References}

1) Al-Gunaid T, Yamaki M, Saito I (2012) Mesiodistal tooth width and tooth size discrepancies of Yemeni Arabians: A pilot study. J Orthod Sci 1:40-45.

2) Anderson AA (2005) Dentition and occlusion development in African American children: mesiodistal crown diameters and tooth-size ratios of primary teeth. Pediatr Dent 27: 121-128.

3) Anderson AA (2007) The dentition and occlusal development in children of African American descent. Angle Orthod 77: 
421-429.

4) Arakawa A, Yonezu T, Tashiro A, Makiguchi T, Imai H, Shintani S (2015) An accuracy and reproducibility of the dental model measurement using dental 3D system. Jpn J Ped Dent 53:114. (in Japanese)

5) Bishara SE, Khadivi P, Jakobson JR (1995) Changes in tooth size-arch length relationships from the deciduous to the permanent dentition: a longitudinal study. Am J Orthod Dentofacial Orthop 108:607-613.

6) Funatsu T, Matsumoto H, Tanaka M (2002) The correlation between deciduous tooth crown size and interdental space in Japanese children. A comparison of the present status with that of 20 years ago. Jpn J Ped Dent 40: 254. (in Japanese)

7) Hanihara K (1966) Deciduous teeth from an anthropological perspective. Dental Outlook 28:11-17. (in Japanese)

8) Huang ST, Miura F, Soma K (1991) A dental anthropological study of Chinese in Taiwan (2). Teeth size, dental arch dimensions and forms. Gaoxiong Yi Xue Ke Xue Za Zhi 7: $635-643$.

9) Inoue N, Ito G, Kamegai T (1986) Small evolution in occlusion and dental disease, A study about discrepancy, pp.53-64, Ishiyaku Publishers, Tokyo. (in Japanese)

10) Japanese Society of Pediatric Dentistry (1993) Research concerning the size of the primary tooth crown, primary dental arch and condition of primary occlusions of the Japanese. Jpn J Ped Dent 31:375-388. (in Japanese)
11) Kaihara $Y$, Katayama A, Ono K, Kurose M, Toma K, Amano H, Nikawa H, Kozai K (2014) Comparative analyses of paediatric dental measurements using plaster and three-dimensional digital models. Eur J Paediatr Dent 15: 137-142.

12) Machida Y (2006) Let's start occlusal guidance, Chapter 2: What we should know about deciduous teeth occlusal guidance, p.45, Issei Publishers, Tokyo. (in Japanese)

13) Meredith HV, Hopp WM (1956) A longitudinal study of dental arch width at the deciduous second molars on children 4 to 8 years of age. J Dent Res 35:879-889.

14) Warren JJ, Bishara ES, Yonezu T (2001) Comparison of dental arch measurements in the primary dentition between contemporary and historical samples. Am J Orthod Dentofacial Orthop 119:211-215.

15) Warren JJ, Bishara ES, Yonezu T (2003) Tooth size-arch length relationships in the deciduous dentition: A comparison between contemporary and historical samples. Am J Orthod Dentofacial Orthop 123:614-619.

\section{Correspondence:}

Dr. Hiroki Imai

Department of Pediatric Dentistry, Tokyo Dental College, 2-9-18 Kanda-Misakicho, Chiyoda-ku, Tokyo 101-0061, Japan E-mail: imai@tdc.ac.jp 